Check for updates

Cite this: RSC Adv., 2019, 9, 12990

\title{
Sealing effect of surface porosity of Ti-P composite films on tinplates
}

\author{
Ziyu Wang, ${ }^{a}$ Delong Kong, ${ }^{a}$ Minghao Wang, ${ }^{a}$ Guixiang Wang, ${ }^{b}$ Ning Li (D) *a \\ and Deyu Li ${ }^{\star a}$
}

A novel chrome-free Ti-P composite film was prepared by casting a mixed solution containing titanium and phosphorus species, which is able to seal the pores on the tinplate surface. The obtained film was characterized using scanning electron microscopy (SEM), energy dispersive X-ray spectroscopy (EDS), and X-ray photoelectron spectroscopy (XPS). The surface porosity sealing effect on tinplates was verified by using a glow discharge spectrometer (GDS), porosity tests, and XPS. The results show that the film on the tinplates is composed of $\mathrm{TiO}_{2}, \mathrm{Ti}_{3}\left(\mathrm{PO}_{4}\right)_{4} \cdot n \mathrm{H}_{2} \mathrm{O}$, and $\mathrm{FePO}_{4}$. Micropores on the tinplates are reduced apparently after film deposition, and the content of iron exposed in the pores is decreased significantly. An obvious concentration peak of phosphorus at a depth of around $0.75 \mu \mathrm{m}$ infers that the film can penetrate into the micro-pores. The film lead to a $42.5 \%$ decrease in the surface porosity of the tinplates, exhibiting an outstanding surface porosity sealing effect in comparison with pure $\mathrm{Ti}$ or $\mathrm{P}$ films. Mechanistic analysis using XPS indicates that $\mathrm{Ti}_{3}\left(\mathrm{PO}_{4}\right)_{4} \cdot n \mathrm{H}_{2} \mathrm{O}$ and $\mathrm{FePO}_{4}$ in the film play a role in sealing the surface porosity.

Received 23rd December 2018 Accepted 22nd April 2019

DOI: $10.1039 / \mathrm{c} 8 \mathrm{ra10523e}$

rsc.li/rsc-advances differences in thickness depending on surface topography of the base steel. ${ }^{2,15}$ Another crucial point is the possible presence of defects such as porosity in the tin layer or the alloy layer., ${ }^{2,6,16}$ Previous studies ${ }^{5,15}$ by means of secondary ion mass spectroscopy analyses have revealed the exposure of Fe-Sn alloy or the base steel through pores on the tinplate, that will cause severe corrosion during storage in humid conditions or usage in food cans. ${ }^{16,17}$ Therefore, a film that can form in the pores and inhibit the corrosion of metals, namely, with a sealing effect on the pores is necessary for the tinplate.

Although the chromium oxide film has demonstrated an excellent controlling effect on the porosity and has been used on the tinplate for a long time, ${ }^{17-20}$ substitutive technologies such as chrome-free conversion film have been developed due to the toxicity of hexavalent chromium in the passivation solution. ${ }^{17,21-23}$ Among researches on chrome-free conversion films, inorganic conversion films and inorganic/organic hybrid films are usually introduced on the tinplate because simplex organic films cannot exhibit a good corrosion performance and are not resistant to high temperature during curing of lacquers, and also, a composite film or multilayer films with complementary performances have become research trends. ${ }^{24-29}$ Considering the pores on the tinplate, strong corrosion resistance of titanium compound film, ${ }^{30-32}$ and beneficial effect of phosphoric acid for iron, ${ }^{33,34}$ a Ti-P (titanium-phosphorus) composite film can be chosen to form a composite conversion film on the tinplate.

In our previous study, a Ti-P composite film was prepared and improved corrosion resistance was noted as a result, ${ }^{35}$
${ }^{a}$ School of Chemistry and Chemical Engineering, Harbin Institute of
Harbin 150001, China. E-mail: lideyuhit@163.com; lininghit@263.net

${ }^{b}$ College of Materials Science and Chemical Engineering, Harbin Engineering University, Harbin 150001, China 
however, the mechanism for the improved anti-corrosion performance still remains unclear. Therefore, in this study, the characterization of the film by morphology observation, elemental analysis, and composite analysis will be carried out, and the sealing effect of the film on the micro-pore will be demonstrated.

\section{Experimental}

Tinplate was fabricated by electrotinning on low carbon steel followed by a reflowing process to form the $\mathrm{Sn}-\mathrm{Fe}$ alloy interlayer. Electrotinning was performed at $1.4 \mathrm{~A} \mathrm{dm}^{-2}$ for $32 \mathrm{~s}$ in a commercial available RONASTAN ${ }^{\mathrm{TM}}$ TP-G7 electrotinning solution (The Dow Chemical Company, America). The reflowing process was then carried out utilizing the high-frequency induction equipment at a power of $650 \mathrm{~W}$ for $0.6 \mathrm{~s}$ to around $300{ }^{\circ} \mathrm{C}$ to form $\mathrm{Fe}-\mathrm{Sn}$ alloy followed by quenching in $50{ }^{\circ} \mathrm{C}$ deionized water. The Ti-P composite conversion film was prepared via roll coating the aqueous solution $\left(1.5 \mathrm{~g} \mathrm{~L} \mathrm{~L}^{-1}\right.$ TiOSO $_{4}, 10 \mathrm{~mL} \mathrm{~L}{ }^{-1} \mathrm{H}_{3} \mathrm{PO}_{4}, 15 \mathrm{~g} \mathrm{~L}^{-1} \mathrm{H}_{2} \mathrm{O}_{2}$ and $0.35 \mathrm{~g} \mathrm{~L}^{-1}$ surfactant) on the tinplate with a wet film thickness of $6 \mu \mathrm{m}$ followed by drying in a vacuum oven at $50{ }^{\circ} \mathrm{C}$ for $90 \mathrm{s.} .^{35}$

Surface morphology characterization and elemental quantification for the tinplate and the conversion film were performed by employing a Helios NanoLab 600i (Thermo Fisher Scientific Inc., America) scanning electron microscope (SEM) coupled with energy dispersive X-ray spectroscopy (EDS). The chemical composition of the conversion film was analyzed by X-ray photoelectron spectroscopy (XPS), using a PHI 5700 ESCA system (Physical Electronics Inc., America) with a monochromatic $\mathrm{Al} \mathrm{K} \alpha(1486.60 \mathrm{eV})$ radiation source. The carbon $\mathrm{C} 1 \mathrm{~s}$ peak at $284.6 \mathrm{eV}$ was adopted as a reference for charge correction, and a standard Shirley background was used for subtraction. ${ }^{36,37}$ Decomposition of the narrow spectrum was undertaken using CasaXPS software (version 2.3.16) with Marquardt-Levenberg fitting procedure and Gaussian (70\%)-Lorentzian (30\%) line shape as defined GL (30) in CasaXPS. Depth profile of the elemental content was analyzed with a GDS750A spectrometer (Leco Corporation, America).

Surface porosity sealing effect of the conversion film was verified by determining the amount of iron dissolved from the micro-pores on the tinplate. The tinplate was fixed to the bottom of a cylindrical container with a $2 \mathrm{~cm}$ inner diameter opening in the middle of the bottom to expose an area of 3.14 $\mathrm{cm}^{2}$. The mixed solution of $30 \mathrm{~mL} 0.66 \mathrm{~mol} \mathrm{~L}^{-1} \mathrm{KSCN}, 30 \mathrm{~mL}$ $0.435 \mathrm{~mol} \mathrm{~L}^{-1} \mathrm{CH}_{3} \mathrm{COOH}, 15 \mathrm{~mL} 1 \mathrm{wt} \% \mathrm{H}_{2} \mathrm{O}_{2}$ and $23.5 \mathrm{~mL}$ deionized water were then added to the container followed by standing at room temperature for $15 \mathrm{~min}$. After that, $1.5 \mathrm{~mL}$ $50 \mathrm{vol} \% \mathrm{H}_{2} \mathrm{SO}_{4}$ solution was further added followed by transferring the solution to another container. Then, the transmittance " $T$ " of the solution was measured at $485 \mathrm{~nm}$ using a 721 visible spectrophotometer (Shanghai Precision Science Instrument Co., Ltd., China). The amount of the dissolved iron was calculated by calibration curve $y=99.78 \exp (-0.195 x)\left(R^{2}=\right.$ 0.9980 ), where $y$ represents the transmittance and $x$ represents the amount value of dissolved iron and expressed in milligrams of dissolved iron per $\mathrm{dm}^{2}$.

\section{Results and discussion}

\subsection{Surface analysis of the tinplate}

Fig. 1 shows the surface morphology of the base steel and the tinplate. It can be seen from Fig. 1a that there exist striations and pits on the surface of the base steel which should be the roll marks formed during the rolling process of the steel. ${ }^{5}$ Fig. $1 \mathrm{~b}$ shows that striations and pits can still be seen on the surface of the tinplate after electrotinning. Meanwhile, it is notable that micro-pores appear on the surface. Since no pores are found on the surface of the base steel (Fig. 1a), the pores are believed to be present in the tin layer. Such pores may result from incomplete coverage of the tin coating. ${ }^{2}$ After reflowing, the micro-pores did not disappear; instead, several micro-pores with larger size appear as shown in Fig. 1c. It indicates that micro-pores can come into being during electrotinning or reflowing process. Further study was carried out by elemental analysis to identify the difference in element content in the micro-pores and the normal area.

Fig. 2 shows energy dispersive spectra at a certain area or a point on the tinplate, and the corresponding results of elemental analysis were listed in Table 1. As described above, there are three layers (Fe-Sn alloy, metallic tin, and tin oxides) on the base steel of a tinplate after reflowing. Consequently, tin, iron, and oxygen are detected on tinplate surface by EDS. The testing area and corresponding spectrum are shown in Fig. 2a, and analyses results are shown in and Table 1 . It can be seen that the atomic percentage of tin is maximum, and the content ratio of tin to iron $(\mathrm{Sn} / \mathrm{Fe})$ is 1.38 . At a certain point in the area without pores (Fig. 2b), the ratio becomes to 3.67 , which is significantly higher than the overall value of 1.38 . It may be due to the existence of the micro-pores where the content of Sn become very low as can be seen from Fig. $2 \mathrm{c}$ and $\mathrm{d}$ and Table 1. In a certain micro-pore (Fig. 2c), the dominant element becomes $\mathrm{Fe}$ and the $\mathrm{Sn} / \mathrm{Fe}$ content ratio decreases by $94.8 \%$ in comparison with the normal area (Fig. 2b), while in another micro-pore (Fig. 2d) the ratio decreases by $97.8 \%$.

The above results demonstrate that micro-pores are present on the surface of tinplate. The content of iron is much higher in micro-pores than in the normal area, indicating that layers of tin and its oxides in the pores are much thinner than that in the normal area. Also, Fe-Sn alloys or the base steels may expose in the pores considering the different layers on the tinplate surface. Due to the evolution of hydrogen occurs during electrotinning, micro-pores are inevitable in the tin layer. Meanwhile, the non-uniform distribution of the current density in micro level due to the rough surface of the base steel as shown in Fig. 1a leads to the uneven thickness distribution of the tin coating. During reflowing process, there is less or even no molten tin in the regions with thinner or without tin coating, and the molten tin will be adequately alloyed with iron, resulting in a much thinner tin layer, or the exposure of $\mathrm{Fe}-\mathrm{Sn}$ alloy or the base steel. Therefore, a protective film with a sealing effect on surface micro-pores is needed on the tinplate. 

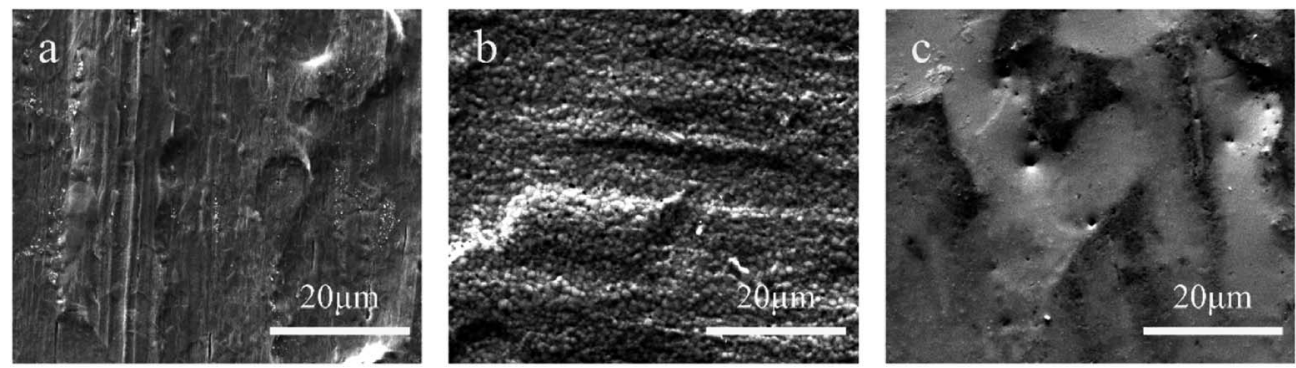

Fig. 1 Surface morphologies of (a) the low carbon steel, (b) tinplate treated with electrotinning, and (c) tinplate treated with electrotinning and reflowing.
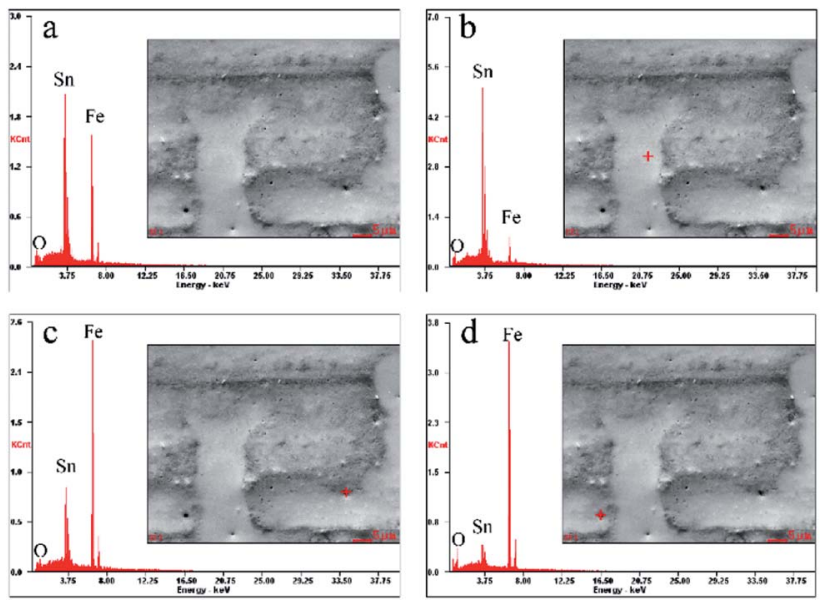

Fig. 2 Energy dispersive spectra from (a) the whole area in the SEM image, (b) a certain point in the normal area, (c) and (d) points in micropores.

Table 1 Atomic percentage content (at.\%) of surface elements in a certain area or at a certain point corresponding to Fig. 2

\begin{tabular}{lrrrr}
\hline Fig. 2 & Sn L & Fe K & O K & Sn/Fe \\
\hline a & 54.29 & 39.31 & 6.40 & 1.38 \\
b & 69.98 & 19.08 & 10.94 & 3.67 \\
c & 15.28 & 81.48 & 3.24 & 0.19 \\
d & 6.78 & 89.84 & 3.37 & 0.08
\end{tabular}

\subsection{Characterization of Ti-P composite film on the tinplate}

3.2.1 Morphology. Morphology observation for the Ti-P composite film by SEM was firstly performed. For comparative study, a simplex $\mathrm{Ti}$ and $\mathrm{P}$ compound film were prepared on tinplates with simplex $\mathrm{Ti}$ (removing $\mathrm{H}_{3} \mathrm{PO}_{4}$ in the mixed solution) and $\mathrm{P}$ (removing TiOSO $_{4}$ and $\mathrm{H}_{2} \mathrm{O}_{2}$ in the mixed solution) system solution. Surface morphologies of tinplates coated with different conversion films are shown in Fig. 3.

It can be seen from Fig. 3a that several tiny particles are sparsely dispersed on the surface of the tinplate coated with a $\mathrm{Ti}$ compound film, whilst micro-pores are still visible. Fig. 3b shows that particles of different sizes and shapes are present on the surface of the tinplate coated with a $\mathrm{P}$ compound film.
Among the particles, some larger ones are in the shape of a flat ellipse with a major axis of around $15 \mu \mathrm{m}$. Comparing with Fig. 3a, the particles in Fig. 3b are much larger and distribute more closely. Moreover, no obvious micro-pore can be found. Fig. 3c shows likewise that a large number of particles are present on the surface of the tinplate coated with a Ti-P composite film, and almost no micro-pore. Nevertheless, comparing with Fig. $3 \mathrm{~b}$, differences lie in the morphology and size of the particles, which are irregular sphere particles with a smaller size of around $6 \mu \mathrm{m}$. This indicates that the morphology of Ti-P composite film is entirely different from either the simplex Ti or the $\mathrm{P}$ compound film. The particles in the composite film are much larger in comparison with the simplex Ti compound film. In contrast, they are finer and more uniform when compared with the individual phosphate films. Also, it can be inferred that the particles could seal the micropores on the tinplate surface. Therefore, the particles were further studied through elemental analysis.

3.2.2 Elemental analysis. Elemental analysis of the particles by EDS was performed to identify the content of titanium and phosphorus. The testing area and corresponding spectrum are shown in Fig. $4 a$ and b, respectively. The spectrum from the central region a particle shows that both Ti and $\mathrm{P}$ elements are detected. The quantitative calculation result of the spectrum indicates that the atomic percentage of $\mathrm{Ti}$ and $\mathrm{P}$ elements are $0.26 \%$ and $7.73 \%$, respectively. The reason for the low content of $\mathrm{Ti}$ is that the concentration of $\mathrm{TiOSO}_{4}$ in the treatment solution is very low, less than $0.02 \mathrm{~mol} \mathrm{~L}^{-1}$. The result also shows the presence of the elements $\mathrm{O}, \mathrm{Sn}$, and $\mathrm{Fe}$ in the central region of the particle. Among all these detected elements, oxygen has the highest atomic percentage content of $73.59 \%$. Since the detection depth of EDS can reach the micron scale, the signal of oxygen may come from the particle or the tin oxide layer. Besides, the content of iron decreases significantly to $7.67 \%$.

From the above results, titanium and phosphorus are detected in the particle, indicating that the particle is composed of compounds of $\mathrm{Ti}$ and $\mathrm{P}$. In the presence of particles, the iron content is significantly reduced, indicating a sealing effect of the particles on the surface pores.

3.2.3 Composition analysis. It has been confirmed that both titanium and phosphorus are present at the tinplate surface coated with a Ti-P composite film. Furthermore, 

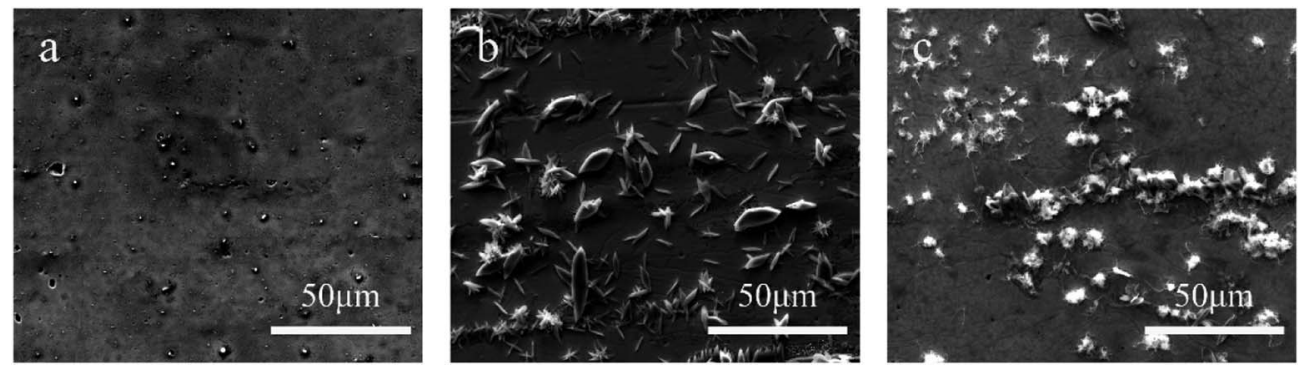

Fig. 3 Surface morphologies of tinplates coated with (a) titanium compound film, (b) phosphate film, and (c) Ti-P composite film.

component analysis for the film was performed by XPS as shown in Fig. 5. For comparative study, analyses for the simplex $\mathrm{Ti}$ and $\mathrm{P}$ compound films were also performed as shown in Fig. $5 \mathrm{a}$ and b, respectively. Fig. $5 \mathrm{a}$ shows that the Ti $2 \mathrm{p}_{3 / 2}$ peak is located at $458.8 \mathrm{eV}$, and the separation " $\Delta E_{\mathrm{b}}$ " between $\mathrm{Ti} 2 \mathrm{p}_{3 / 2}$ and Ti $2 \mathrm{p}_{1 / 2}$ peaks is $5.9 \mathrm{eV}$. Comparing with the standard spectrum of $\mathrm{Ti}$ in $\mathrm{TiO}_{2}\left(\mathrm{Ti} 2 \mathrm{p}_{3 / 2}: E_{\mathrm{b}}=458.8 \mathrm{eV}, \Delta E_{\mathrm{b}}=5.54 \mathrm{eV}\right),{ }^{38}$ it can be inferred that the titanium compound is $\mathrm{TiO}_{2}$. In Fig. 5b, the optimized fitting results of $\mathrm{P} 2 \mathrm{p}$ peak shows only one peak at $133.6 \mathrm{eV}$. When it comes to the standard data of $\mathrm{P} 2 \mathrm{p}$ peak, the $\Delta E_{\mathrm{b}}$ between $2 \mathrm{p}_{3 / 2}$ and $2 \mathrm{p}_{1 / 2}$ is only $0.84 \mathrm{eV},{ }^{38}$ that is the overlap of two peaks and are difficult to separate. According to references, ${ }^{39,40}$ it can be deduced that the phosphate film on the tinplate is mainly composed of $\mathrm{FePO}_{4}$. The above results indicate that in the simplex titanium system and phosphorus system, $\mathrm{TiO}_{2}$ and $\mathrm{FePO}_{4}$ can be formed on the tinplate surface, respectively.

Concerning the film formed in the Ti-P mixed system, the XPS spectra of Ti $2 p$ and $P$ 2p peaks are shown in Fig. $5 c$ and d. In comparison with Fig. 5a, Fig. $5 c$ exhibits a broader Ti $2 \mathrm{p}_{3 / 2}$ peak, which can be decomposed into two peaks with $E_{\mathrm{b}}=$ $458.0 \mathrm{eV}$ and $459.1 \mathrm{eV}$, and the $\Delta E_{\mathrm{b}}$ between Ti $2 \mathrm{p}_{3 / 2}$ and Ti $2 \mathrm{p}_{1 / 2}$ is respectively $6.1 \mathrm{eV}$ and $6.2 \mathrm{eV}$. The differences indicate that the Ti-P composite film contains different compounds of titanium instead of pure $\mathrm{TiO}_{2}$. However, the $\Delta E_{\mathrm{b}}$ is acceptable which is close to $6.17 \mathrm{eV}$ as reported in reference. ${ }^{38}$ With regard to the binding energy, Castillo (1996) ${ }^{41}$ has reported in his research that the Ti $2 \mathrm{p}_{3 / 2}$ peak of $\mathrm{TiO}_{2}$ is located at $485.0 \mathrm{eV}$, meanwhile, $\mathrm{TiO}_{2}$ has been confirmed as a component of the titanium compound film, thus, it can be inferred that $\mathrm{TiO}_{2}$ is as well a component of the Ti-P composite film. Hanawa (1991 ${ }^{42}$ has reported in his research that a Ti $2 \mathrm{p}_{3 / 2}$ peak located at $459.0 \mathrm{eV}$ is from $\mathrm{Ti}_{3}\left(\mathrm{PO}_{4}\right)_{4} \cdot n \mathrm{H}_{2} \mathrm{O}$, as a reference, the peak with an approximate $E_{\mathrm{b}}(459.1 \mathrm{eV})$ can be seen as from the same substance.

The $\mathrm{P} 2 \mathrm{p}$ peak (see in Fig. 5d) is decomposed into two peaks with $E_{\mathrm{b}}=133.6 \mathrm{eV}$ and $134.4 \mathrm{eV}$, and the $\Delta E_{\mathrm{b}}$ between them is $0.8 \mathrm{eV}$, close to the $\Delta E_{\mathrm{b}}$ between $\mathrm{P} 2 \mathrm{p}_{3 / 2}$ and $\mathrm{P} 2 \mathrm{p}_{1 / 2}$ peaks. As described above, the $\mathrm{P} 2 \mathrm{p}$ peak from $\mathrm{FePO}_{4}$ is located at $133.6 \mathrm{eV}$, and as reported by Hanawa (1991), ${ }^{42}$ the $\mathrm{P} 2 \mathrm{p}$ peak of $\mathrm{Ti}_{3}\left(\mathrm{PO}_{4}\right)_{4} \cdot n \mathrm{H}_{2} \mathrm{O}$ is also with an $E_{\mathrm{b}}$ of $133.6 \mathrm{eV}$. Combining the analysis for $\mathrm{P} 2 \mathrm{p}$ peak of the phosphate film and Ti $2 \mathrm{p}$ peak of the Ti-P composite film, it can be deduced that both $\mathrm{FePO}_{4}$ and $\mathrm{Ti}_{3}\left(\mathrm{PO}_{4}\right)_{4} \cdot n \mathrm{H}_{2} \mathrm{O}$ are the components of Ti-P the composite film. In summary, the film is confirmed to be a composite film of $\mathrm{Ti}$ and $\mathrm{P}$ compounds, that is $\mathrm{TiO}_{2}, \mathrm{Ti}_{3}\left(\mathrm{PO}_{4}\right)_{4} \cdot n \mathrm{H}_{2} \mathrm{O}$ and $\mathrm{FePO}_{4}$.

\subsection{Sealing effect of the film for the tinplate}

3.3.1 GDS depth profile. In the previous studies, a sealing effect of the Ti-P composite film was proposed since micropores on the tinplate were found disappeared after the film formation as shown in Fig. 3d. Given this, investigations will be carried out to verify and further study the sealing effect. The content variation of the elements on the tinplate was firstly examined by GDS. Fig. 6 shows the GDS depth profile of the elements on the tinplate before and after the formation of the Ti-P composite film.

As shown in Fig. 6a, the concentration of iron begins to increase at a depth of $0.5 \mu \mathrm{m}$, while the concentration of tin
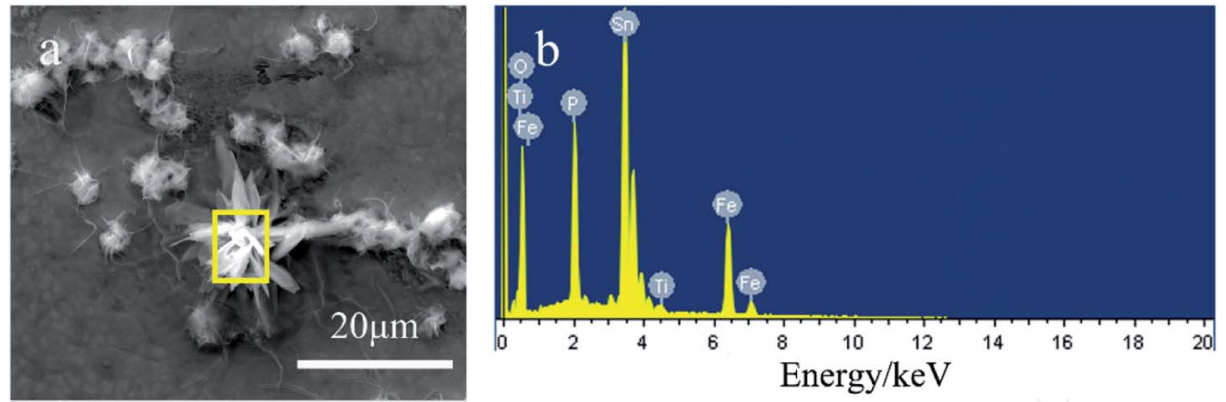

Fig. 4 Elemental analysis of the tinplate coated with a Ti-P composite film, (a) surface morphology of the testing area (b) energy dispersive spectra. 

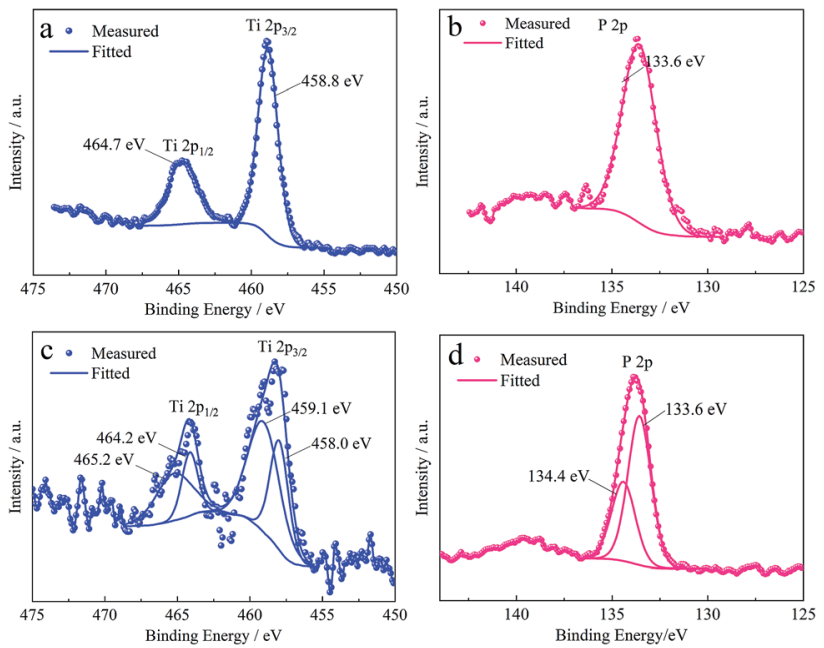

Fig. 5 XPS spectra of Ti $2 p$ and P $2 p$ from the surface of tinplates (a) coated with a titanium compound film, (b) coated with a phosphate film, (c) and (d) coated with a Ti-P composite film.
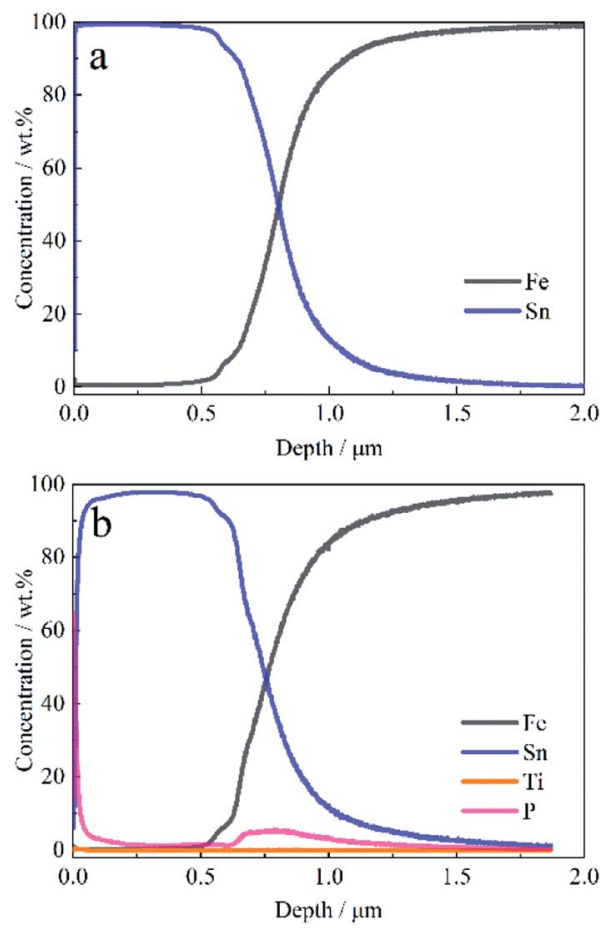

Fig. 6 GDS depth profile of the elements on the tinplate (a) without films, and (b) coated with a Ti-P composition film.

begins to decrease, indicating that the Fe-Sn alloy layer has been reached at this depth. On the surface of the tinplate coated with a Ti-P composite film, the concentration of phosphorus is higher than that of the titanium (see in Fig. 6b), which is corresponding with the results of EDS. Moreover, both the concentrations of Ti and $\mathrm{P}$ decrease with depth in the range of 0-0.5 $\mu \mathrm{m}$. Nevertheless, an obvious concentration peak of phosphorus is present at a depth of around $0.75 \mu \mathrm{m}$, and phosphorus is detected to be present in the depth range of 0.6-
1.0 $\mu \mathrm{m}$. Compared with Fig. 6a, it can be known that the phosphorus in the internal tinplate is derived from the film rather than the base steel. It indicates that the film is also present in the internal tinplate, that is, the film is present in micro-pores and has a sealing effect on the pores.

3.3.2 Porosity test. Porosity test was then carried out to characterize the sealing performance. When the tinplate is placed in a corrosive solution, corrosion of iron and dissolution of iron ions will occur preferentially in micro-pores where the content of iron is at a high level. If a weakly corrosive solution is used and the corrosion time is limited, corrosion of the other regions can be avoided, and iron dissolution from micropores can be selectively achieved. Given this, acetic acid is chosen as the corrosive component, hydrogen peroxide as the oxidant for $\mathrm{Fe}^{2+}$, and KSCN as the color-developing agent in the corrosive solution. After corrosion for $15 \mathrm{~min}$, a small amount of sulfuric acid is added to the solution to prevent colloid formation. Then, the amount of the dissolved iron can be determined via spectrophotometry - the less the amount of dissolved iron, the lower the porosity and the better the sealing effect.

Table 2 exhibits the results of porosity tests for the tinplates. Three different regions are selected randomly for parallel testing, and the average was calculated. As exhibited in Table 2, there are no distinct changes on the porosity of the tinplate coated with a titanium compound film (mainly $\mathrm{TiO}_{2}$, see the previous study) in comparison with that of the tinplate without a conversion film. According to previous studies, the content of Ti on the tinplate is low, and tiny particles sparsely dispersed at the surface. Therefore, the sealing effect of the film is limited, resulting in a slight decrease of $2.3 \%$ in the average. The average of the tinplate coated with a phosphate film decreases by $12.7 \%$ compared with that of the tinplate without a conversion film, indicating a better sealing effect than the titanium compound film. It is because the iron on the tinplate has reacted with phosphoric acid to form a film of which the main component is $\mathrm{FePO}_{4}$, and several larger particles distributed on the surface as shown in Fig. 3c where no obvious micro-pores can be found. When it comes to the tinplate coated with a Ti-P composite film, the average decreases by $42.5 \%$, implying that the composite film has a significant improvement in sealing effect. It is known from the morphology and composition of the film mentioned above that the composite film is quite different from the simplex $\mathrm{Ti}$ and $\mathrm{P}$ compound films. The particles in the composite film are finer and more uniform in size, and the reaction of $\mathrm{Ti}$ and $\mathrm{P}$ components generates a new composition of $\mathrm{Ti}_{3}\left(\mathrm{PO}_{4}\right)_{4} \cdot n \mathrm{H}_{2} \mathrm{O}$, which significantly improves the sealing effect of the composite film. Therefore, the Ti-P composite film has an outstanding surface porosity sealing effect.

3.3.3 Mechanism analysis. As described in the preceding study, ultrathin layers of tin and its oxides, as well as Fe-Sn alloy and the base steel, may be present in micro-pores. In the first case mentioned above, there is no difference in the formation of the film in a pore and a normal area on the tinplate surface. However, in the latter two cases, the formation of the film on the alloy layer and the base steel needs to be investigated. The FeSn alloy layer was prepared by immersing the reflowing tinplate in an etching solution $\left(50 \mathrm{~g} \mathrm{~L}^{-1} \mathrm{NaOH} \text { and } 10 \mathrm{~g} \mathrm{~L}^{-1} \mathrm{KIO}_{3}\right)^{6}$ for 
Table 2 Results of porosity test on tinplates without or with different conversion films $\left(\mathrm{mg} \mathrm{dm}^{-2}\right)$

\begin{tabular}{lccr}
\hline Tinplate sample & Region 1 & Region 2 & Region 3 \\
\hline Without films & 13.71 & 14.22 & 14.01 \\
With a titanium compound & 14.13 & 13.26 & 13.58 \\
film & & & 13.980 \\
With a phosphate film & 12.59 & 12.17 & 11.85 \\
With a Ti-P composite film & 7.19 & 8.23 & 8.69 \\
\end{tabular}

$30 \mathrm{~min}$ at room temperature. Films were prepared on the Fe-Sn alloy and the base steel via the same process as the preparation of Ti-P composite film on the tinplate. XPS spectra of Ti $2 \mathrm{p}$ and $\mathrm{P} 2 \mathrm{p}$ peaks are shown in Fig. 7.

Fig. 7a shows Ti $2 \mathrm{p}_{3 / 2}$ peak can be fitted with only one peak located at $459.0 \mathrm{eV}$, which means the titanium is present mainly in the form of $\mathrm{Ti}_{3}\left(\mathrm{PO}_{4}\right)_{4} \cdot n \mathrm{H}_{2} \mathrm{O}$ on the surface of $\mathrm{Fe}-\mathrm{Sn}$ alloy according to the preceding XPS analysis. As shown in Fig. 7b, the $\mathrm{P} 2 \mathrm{p}$ peak is decomposed into two peaks with $E_{\mathrm{b}}$ of $133.3 \mathrm{eV}$ and $134.1 \mathrm{eV}$, respectively. Although the binding energy of $\mathrm{P} 2 \mathrm{p}$ shifts $0.3 \mathrm{eV}$ in comparison with that in Fig. $5 \mathrm{~d}$, from the $\Delta E_{\mathrm{b}}$ $(0.8 \mathrm{eV})$ and the Ti $2 \mathrm{p}$ peaks, it can be inferred that phosphorus is present in the form of $\mathrm{Ti}_{3}\left(\mathrm{PO}_{4}\right)_{4} \cdot n \mathrm{H}_{2} \mathrm{O}$ and $\mathrm{FePO}_{4}$ on the surface of Fe-Sn alloy. From the Ti 2p peak, as shown in Fig. 7c, it is known that the content of titanium on the surface of the base steel is very low since the signal is weak and interfered. The $E_{\mathrm{b}}(458.9 \mathrm{eV})$ of Ti $2 \mathrm{p}_{3 / 2}$ and the $\Delta E_{\mathrm{b}}(5.7 \mathrm{eV})$ are close to those in Fig. 7a, indicating that the titanium is as well derived from the $\mathrm{Ti}_{3}\left(\mathrm{PO}_{4}\right)_{4} \cdot n \mathrm{H}_{2} \mathrm{O}$. Also, Fig. $7 \mathrm{~d}$ shows a similar decomposition result of $\mathrm{P} 2 \mathrm{p}$ peak to Fig. $7 \mathrm{~b}$. Thus, the same conclusion can be drawn as well. In summary, the Ti-P composite film can be formed both on the surface of the $\mathrm{Fe}-\mathrm{Sn}$ alloy and the base steel, and the composition of both the films are $\mathrm{Ti}_{3}\left(\mathrm{PO}_{4}\right)_{4} \cdot n \mathrm{H}_{2} \mathrm{O}$ and $\mathrm{FePO}_{4}$. The Ti-P mixed system can also form a film in the pores where the alloy layer or the base steel expose. As a result, the surface porosity of the tinplate decreases.
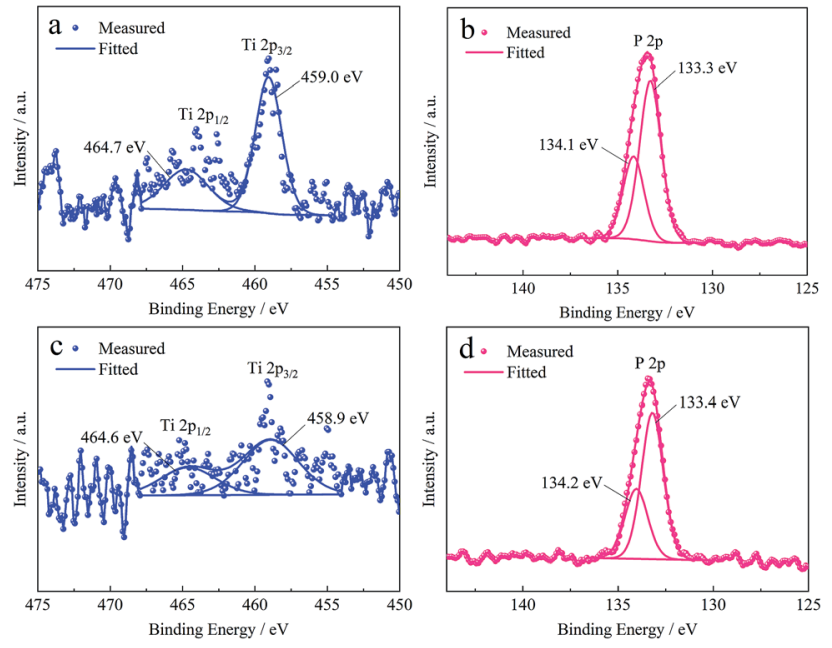

Fig. 7 XPS spectra of Ti $2 p$ and P 2p from the surface of (a), (b) Fe-Sn alloy and (c), (d) base steel treated with Ti-P mixed system, respectively.
Nevertheless, it is notable that the composition of the films on the Fe-Sn alloy and the base steel is different from that of the film on the normal tinplate as the absence of the component $\mathrm{TiO}_{2}$. Combining the results of the morphology and porosity of the tinplate coated with a $\mathrm{TiO}_{2}$ film as shown in Fig. $3 \mathrm{~b}$ and Table 2, it can be deduced that the $\mathrm{TiO}_{2}$ in the $\mathrm{Ti}-\mathrm{P}$ composite film does not have a sealing effect on the micro-pores.

Changes in the composition of tin and iron compounds involved in the reaction of the film formation were investigated by XPS to study the mechanism of the formation and sealing effect of the film further. Fig. 8a shows the Sn 3d spectra from the surface of the tinplate without a conversion film. The $S n 3 d_{5 /}$ 2 peak is decomposed into two peaks which are located at $486.0 \mathrm{eV}$ and $484.1 \mathrm{eV}$, and the corresponding $\Delta E_{\mathrm{b}}$ between $3 \mathrm{~d}_{5 / 2}$ and $3 \mathrm{~d}_{3 / 2}$ peaks are $0.84 \mathrm{eV}$ and $0.85 \mathrm{eV}$, respectively. The former decomposed peak is derived from SnO according to the reference, ${ }^{38}$ and the latter is considered to be the peak of metallic tin since the outer layers of tinplate are the tin oxide and metallic tin as described above. After the formation of the Ti-P composite film, the peak position of $S n 3 d_{5 / 2}$ peak shifts positively by $0.8 \mathrm{eV}$ as shown in Fig. $8 \mathrm{~b}$, and the decomposed peak at the corresponding position of the metallic tin almost disappear. As reported by Choi, ${ }^{43}$ the $\mathrm{Sn} 3 \mathrm{~d}_{5 / 2}$ peak located at $486.75 \mathrm{eV}$ with a $\Delta E_{\mathrm{b}}$ of $8.42 \mathrm{eV}$ is derived from $\mathrm{SnO}_{2}$. In comparison, the $\mathrm{Sn} 3 \mathrm{~d}_{5 / 2}$ peak located at $486.8 \mathrm{eV}$ with a $\Delta E_{\mathrm{b}}$ of $8.4 \mathrm{eV}$ as shown
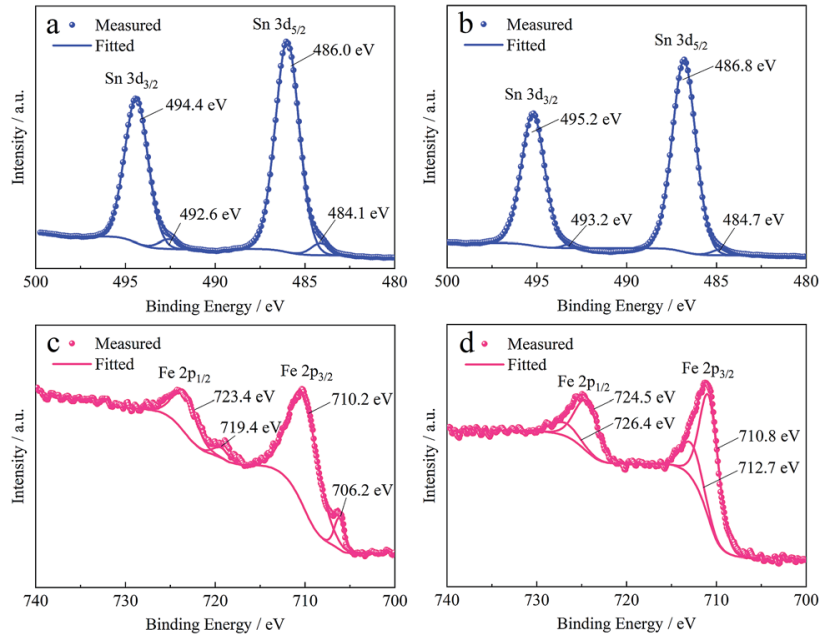

Fig. 8 XPS spectra of Sn $3 d$ from the surface of the tinplate (a) without films and (b) with a Ti-P composite film; XPS spectra of Fe $2 p$ form the surface of the base steel (c) without films and (d) with a Ti-P composite film. 
in Fig. $8 \mathrm{~b}$ is from $\mathrm{SnO}_{2}$. It indicates that the tin oxide was further oxidated from $\mathrm{SnO}$ to $\mathrm{SnO}_{2}$ during the formation process of the film.

Changes of iron compounds after the coverage of the film were investigated on the base steel since iron was present in the inner layer and cannot be detected using XPS at the surface of the tinplate. Fig. $8 \mathrm{c}$ shows the Fe 2 p spectra from the base steel. As shown in Fig. 8c, the two decomposed peaks in Fe $2 \mathrm{p}_{3 / 2}$ peak are respectively located at $710.2 \mathrm{eV}$ and $706.2 \mathrm{eV}$, and the $\Delta E_{\mathrm{b}}$ between $2 \mathrm{p}_{3 / 2}$ and $2 \mathrm{p}_{1 / 2}$ peaks are both $13.2 \mathrm{eV}$. The former decomposed peak is considered to be derived from $\mathrm{Fe}_{3} \mathrm{O}_{4}$ referring to the previous study, ${ }^{\mathbf{4}}$ and the latter is believed to be the peak of metallic iron. After the formation of the Ti-P composite film, the peak position of Fe $2 \mathrm{p}$ shift positively as shown in Fig. 8d. The two decomposed peaks in Fe $2 \mathrm{p}_{3 / 2}$ peak are located at $712.8 \mathrm{eV}$ and $710.8 \mathrm{eV}$, and the $\Delta E_{\mathrm{b}}$ between $2 \mathrm{p}_{3 / 2}$ and $2 \mathrm{p}_{1 / 2}$ peaks are both $13.7 \mathrm{eV}$. The two decomposed peaks are considered to be derived from $\mathrm{FePO}_{4}$ and $\mathrm{Fe}_{3} \mathrm{O}_{4}$ according to the previous studies, ${ }^{\mathbf{4 5 , 4 6}}$ respectively. The results exhibit more $\mathrm{Fe}(\mathrm{III})$ compounds are present on the surface, indicating that iron and its compounds are also oxidated during the formation process of the film.

From the above results, it can be deduced that redox reaction occurs during the process of the Ti-P composite film formation on the tinplate. The $\mathrm{H}_{2} \mathrm{O}_{2}$ in the Ti-P mixed solution which acts as the complexing agent for $\mathrm{TiO}^{2+}$ has an oxidation effect for the oxides of iron and tin as well. With the consumption of $\mathrm{H}_{2} \mathrm{O}_{2}$ in the redox reaction, $\mathrm{TiO}^{2+}$ loses its ligand, resulting in the generation of $\mathrm{TiO}_{2}$ and $\mathrm{Ti}_{3}\left(\mathrm{PO}_{4}\right)_{4} \cdot n \mathrm{H}_{2} \mathrm{O}$. In the micro-pores on the tinplate, the exposed iron and its oxides can be converted into $\mathrm{Fe}^{2+}$ and $\mathrm{Fe}^{3+}$ by $\mathrm{H}^{+}$and then generating $\mathrm{FePO}_{4}$ with the presence of $\mathrm{H}_{2} \mathrm{O}_{2}$ and $\mathrm{PO}_{4}{ }^{3-}$ in the solution. Thereby, a Ti-P composite film, which composes of $\mathrm{TiO}_{2}, \mathrm{Ti}_{3}\left(\mathrm{PO}_{4}\right)_{4} \cdot n \mathrm{H}_{2} \mathrm{O}$ and $\mathrm{FePO}_{4}$, is formed on the tinplates. The components of $\mathrm{Ti}_{3}(-$ $\left.\mathrm{PO}_{4}\right)_{4} \cdot n \mathrm{H}_{2} \mathrm{O}$ and $\mathrm{FePO}_{4}$ in the film generate the sealing effect on surface micro-pores.

\section{Conclusions}

This work reported a novel chrome-free Ti-P composite conversion film on tinplates. The formation process of the film and the possible sealing effect on surface micro-pores have been comprehensively investigated. Morphology characterization shows that the film consists of irregular sphere particles with a size of around $6 \mu \mathrm{m}$. The film is mainly composed of $\mathrm{TiO}_{2}, \mathrm{Ti}_{3}\left(\mathrm{PO}_{4}\right)_{4} \cdot n \mathrm{H}_{2} \mathrm{O}$, and $\mathrm{FePO}_{4}$. Both the number of micropores formerly existing on tinplates surface and the exposed iron in micro-pores were significant decreased. GDS examines present an obvious concentration peak of phosphorus at a depth of around $0.75 \mu \mathrm{m}$. Porosity tests indicate a decrease in surface porosity by $42.5 \%$ after film deposition. The decreased values for individual $\mathrm{TiO}_{2}$ and $\mathrm{FePO}_{4}$ films are only $2.3 \%$ and $12.7 \%$, respectively. The results reveal that the film can form into micro-pores and show an outstanding sealing effect on the micro-pores. $\mathrm{Ti}_{3}\left(\mathrm{PO}_{4}\right)_{4} \cdot n \mathrm{H}_{2} \mathrm{O}$ and $\mathrm{FePO}_{4}$ in the film are crucial for the sealing effect on the micro-pores exposed Fe-Sn alloy and/or the base steel. Both oxidations from $\mathrm{SnO}$ to $\mathrm{SnO}_{2}$ and from iron to Fe(III) occur during the formation of the film. This study has solved the surface porosity problem of tinplates by using the newly invented Ti-P composite film.

\section{Conflicts of interest}

There are no conflicts to declare.

\section{References}

1 S. Blunden and T. Wallace, Food Chem. Toxicol., 2003, 41, 1651-1662.

2 F. C. Caiazzo, L. Brambilla, A. Montanari and S. Mischler, Surf. Interface Anal., 2018, 50, 430-440.

3 H. E. Biber, J. Electrochem. Soc., 1966, 113, 362-365.

4 H. E. Biber and W. Harter, J. Electrochem. Soc., 1966, 113, 828-834.

5 S. Ramamurthy, T. L. Walzak, S. F. Lu, T. C. Lipson and N. S. McIntyre, Surf. Interface Anal., 1991, 17, 834-841.

6 G. F. Cui, J. H. Wang, N. Li and X. Q. Huang, Mater. Chem. Phys., 2006, 97, 488-493.

7 T. Y. Kim, Y. S. Jin and K. Y. Kim, Surf. Coat. Technol., 1998, 99, 319-325.

8 A. N. Grassino, Z. Grabaric, A. Pezzani, G. Fasanaro and A. Lo Voi, Food Chem. Toxicol., 2009, 47, 1556-1561.

9 M. C. Biermann, PhD thesis, University of Pretoria, Pretoria, 2005.

10 N. Mora, E. Cano, J. L. Polo, J. M. Puente and J. M. Bastidas, Corros. Sci., 2004, 46, 563-578.

11 S. Chen, L. Xie and F. Xue, Appl. Surf. Sci., 2013, 276, 454457.

12 M. Wang, Z. Wang, D. Li and N. Li, Coatings, 2018, 8, 94.

13 S. C. Britton and J. C. Sherlock, Br. Corros. J., 1974, 9, 96-102. 14 P. Rocquet and P. Aubrun, Br. Corros. J., 1970, 5, 193-197.

15 S. F. Lu, G. R. Mount, N. S. McIntyre and A. Fenster, Surf. Interface Anal., 1994, 21, 177-183.

16 J. G. Huang, N. Li and D. R. Zhou, J. Cent. South Univ. Technol., 2004, 11, 362-366.

17 M. A. Arenas, A. Conde and J. J. de Damborenea, Corros. Sci., 2002, 44, 511-520.

18 J. M. Bastidas, J. M. Cabanes and R. Catala, Prog. Org. Coat., 1997, 30, 9-14.

19 E. Zumelzu and C. Cabezas, Mater. Charact., 1995, 34, 143148.

20 R. Neish and J. Donelson, Food Technol., 1960, 14, 37-42.

21 X. Huang and N. Li, Appl. Surf. Sci., 2007, 254, 1463-1470.

22 D. Alvarez, A. Collazo, X. R. Novoa and C. Perez, Prog. Org. Coat., 2014, 77, 2066-2075.

23 D. Alvarez, A. Collazo and C. Perez, Surf. Coat. Technol., 2017, 321, 108-117.

24 Y. Kiyota and M. Matsunaga, ECS Trans., 2008, 11, 43-46.

25 E. Almeida, N. De Cristofaro, N. Mora, J. M. Bastidas and J. M. Puente, JCT Res., 2004, 1, 103-109.

26 D. Yfantis, A. Yfantis, B. Tzalas and D. Schmeisser, Corrosion, 2000, 56, 700-708. 
27 S. R. Kunst, L. V. R. Beltrami, H. R. P. Cardoso, J. A. Santana, V. H. V. Sarmento, I. L. Müller and C. D. F. Malfatti, Mater. Res., 2015, 18, 151-163.

28 E. K. K. Baldin, S. R. Kunst, L. V. R. Beltrami, T. M. Lemos, M. C. Quevedo, A. C. Bastos, M. G. S. Ferreira, P. R. R. Santos, V. H. V. Sarmento and C. D. F. Malfatti, Thin Solid Films, 2016, 600, 146-156.

29 S. R. Kunst, H. R. P. Cardoso, C. T. Oliveira, J. A. Santana, V. H. V. Sarmento, I. L. Muller and C. F. Malfatti, Appl. Surf. Sci., 2014, 298, 1-11.

30 X. Huang and N. Li, J. Alloys Compd., 2008, 465, 317-323.

31 E. Almeida, M. R. Costa, N. De Cristofaro, N. Mora, R. Catalá, J. M. Puente and J. M. Bastidas, Corros. Eng., Sci. Technol., 2005, 40, 158-164.

32 R. Catala, M. Alonso, R. Gavara, E. Almeida, J. M. Bastidas, J. M. Puente and N. de Cristaforo, Food Sci. Technol. Int., 2005, 11, 223-227.

33 A. Ragheb and L. A. Kamel, Corrosion, 1962, 18, 153t-157t. 34 T. Ohga, H. Miyazaki and M. Yamamoto, Zairyo to Kankyo, 1997, 46, 771-776.

35 Z. Wang, M. Wang, D. Li and N. Li, J. Electrochem., 2018, 24, 13-19.
36 T. Yamashita and P. Hayes, Appl. Surf. Sci., 2008, 254, 24412449.

37 M. C. Biesinger, B. P. Payne, L. W. M. Lau, A. Gerson and R. S. C. Smart, Surf. Interface Anal., 2009, 41, 324-332.

38 J. F. Moulder, Handbook of X-ray photoelectron spectroscopy, 1995.

39 Y. Barbaux, M. Dekiouk, D. Lemaguer, L. Gengembre, D. Huchette and J. Grimblot, Appl. Catal., A, 1992, 90, 51-60.

40 R. Franke, T. Chasse, P. Streubel and A. Meisel, J. Electron Spectrosc. Relat. Phenom., 1991, 56, 381-388.

41 R. Castillo, B. Koch, P. Ruiz and B. Delmon, J. Catal., 1996, 161, 524-529.

42 T. Hanawa and M. Ota, Biomaterials, 1991, 12, 767-774.

43 W. K. Choi, H. J. Jung and S. K. Koh, J. Vac. Sci. Technol., A, 1996, 14, 359-366.

44 B. J. Tan, K. J. Klabunde and P. M. A. Sherwood, Chem. Mater., 1990, 2, 186-191.

45 D. D. Hawn and B. M. Dekoven, Surf. Interface Anal., 1987, 10, 63-74.

46 P. Mills and J. L. Sullivan, J. Phys. D: Appl. Phys., 1983, 6, 723. 